\title{
Socio-Demographic and Economic Characteristics Associated with Current Use of a Modern Contraceptive Method by Women in Kita, Mali
}

\author{
Famagan-Oulé Konate ${ }^{1}$, Niapegué Pierre Cisse ${ }^{2}$, Mariam F. Konate ${ }^{2 *}$ \\ ${ }^{1}$ The Private University Centre DELTA-C Bamako (IPU), Bamako, Mali \\ ${ }^{2}$ The Institut de Pédagogie Universitaire de Bamako (IPU), Bamako, Mali \\ Email: famagankonate@yahoo.fr, pierrecisse22@hotmail.fr, *mariamfamagankonate@yahoo.fr
}

How to cite this paper: Konate, F.-O., Cisse, N. P., \& Konate, M. F. (2021). Socio-Demographic and Economic Characteristics Associated with Current Use of a Modern Contraceptive Method by Women in Kita, Mali. Open Journal of Social Sciences, 9, 338-352. https://doi.org/10.4236/jss.2021.99024

Received: July 29, 2021

Accepted: September 12, 2021

Published: September 15, 2021

Copyright $\odot 2021$ by author(s) and Scientific Research Publishing Inc. This work is licensed under the Creative Commons Attribution International License (CC BY 4.0).

http://creativecommons.org/licenses/by/4.0/

(c) (i) Open Access

\begin{abstract}
The objective of this study is to analyse the socio-demographic and economic characteristics associated with the current use of a modern contraceptive method by women in Kita, Mali. This research is of interest because it will determine the nature of individual and economic determinants associated with current use of modern contraception. The methodology was based on a literature search and a quantitative survey and analytical study (bivariate analysis). The questionnaire was administered to a random sample of 281 women aged 15 - 49 years who had had at least one child. The bivariate logistic regression analysis revealed socio-demographic and economic characteristics associated with current use of a modern contraceptive method. The study found that $19.6 \%$ of women of reproductive age [WRA] were using a contraceptive method at the time of the survey. The characteristics associated with this practice are: age, number of living children, level of knowledge of modern contraceptives, the woman's attitude towards contraception, the identity of the person who decides on all care in the household, and the level of education. In contrast, marital status and access to family planning information are not statistically significantly associated with current contraceptive use by [WRA]. Consideration of these relevant characteristics will improve the effectiveness of ongoing family planning programmes in this city.
\end{abstract}

\section{Keywords}

Contraceptives, Characteristics, Women, Family Planning, Mali 


\section{Introduction}

At the July 2012 London conference on family planning, partners decided to establish the global initiative for [FP], known as [FP2020], to reduce maternal mortality. As a result of these conferences, Mali developed a Plan of Action for Repositioning Family Planning, 2014-2018.

According to the United Nations Population Fund (UNFPA, 2017: pp. 18-22), Mali has ratified numerous international conventions and charters related to reproductive rights and health, including: the International Convention on the Rights of the Child [ICRC] in 1990, the African Charter on Human and Peoples' Rights in 1981... At the national level, the Government has enacted and adopted several laws or texts contributing to the implementation of international conventions. While some of these texts represent a legislative and legal advance towards greater equality between men and women and recognition of health and reproductive rights, Malian legislation remains poorly harmonised with international human rights texts. The law on reproductive health (02-04, 24 June 2002) states that "men and women have equal rights and dignity in matters of reproductive health". It implies the right for women and men to be informed, to use the planning method of their choice, "to access reproductive health services and to benefit from the best possible quality of care". Nevertheless, Mali faces problems in the application of this law: insufficient dissemination of the law, the lack of structures for the provision of appropriate Reproductive Health Care [RHC] services, and persistent prejudices that limit these services to married couples. The law also does not provide for free contraceptives for minors, which may limit access to these services. In addition, the reference to "respect for public order and family morality" in Article 12, which authorises "information and education concerning contraception", may be interpreted in such a way as to discourage access to information for young people.

And for Vimard (2007: pp. 350-353), unmarried young people often have difficult access to reproductive health services, which explains their low use of contraception, especially modern methods, and their frequent recourse to voluntary termination of pregnancy.

Modern contraception is relatively recent in Mali. Its history is closely linked to that of the Association Malienne pour la Protection et al. Promotion de la Famille (AMPPF), a national non-profit NGO created on 3 March 1972.

The level of contraceptive prevalence in sub-Saharan Africa varies from country to country, but rarely reaches $40 \%$ : Institut National de la Statistique (INSTAT) du Mali (2014: pp. 77-120; 2019: p. 6); Agence Nationale de la Statistique et de la Démographie (ANSD) du Sénégal (2020: pp. 137-195); Institut National de la Statistique Ministère du Plan et du Développement Economique Conakry, Guinea (2019: pp. 163-170); Institut National de la Statistique (INS) du Tchad (2015: pp. 1-11); Institut National de la Statistique (INS) du Niger (2013: pp. 8-40). According to the extensive literature from the Demographic and Health Surveys (cited above), the characteristics associated with contraceptive use are: age, ma- 
rital status, level of education, place of residence and number of living children. For other characteristics such as marital status, ideal number of children, there are variations. Almost all of the above results have been broken down to the level of the regional capitals. Very few studies have been carried out on the other cities. The results of this research in a medium-sized town in Mali will make it possible to fill this gap in part.

This observation led us to conduct a study on the socio-demographic and economic characteristics associated with current use of a modern contraceptive method by [WRA] in Kita. The aim is to determine the most relevant characteristics associated with this type of contraception among [WRA]. To achieve this objective, our argument is based on the general hypothesis that socio-demographic and economic characteristics are variously associated in a statistically significant way with current use of modern contraception by [WRA] in Kita.

\section{Methodology}

\subsection{Scope of the Study}

The town of Kita, capital of the Kita circle, in the Kayes region, is the field of this study (Map 1). Its geographical coordinates are: $13^{\circ} 03^{\prime} 00^{\prime \prime}$ North, $9^{\circ} 29^{\prime} 00^{\prime \prime}$ West. The city has an area of $11.514 \mathrm{~km}^{2}$ and a population of 65,908 inhabitants in 2020, of which 32,295 are men and 33,613 are women (Ministry of Land Use and Population, Population Projections, 2020: pp. 14-20). In terms of health, the town has 2 Community Health Centres [CSCOM], 1 Reference Health Centre [CSREF] and 8 private clinics. The 112 health workers are distributed as follows: doctors (13.4\%), midwives (8.9\%), obstetric nurses (31.3\%), nurses (19.6\%), nurses' aides (3.6\%), matrons (13.4\%) and laboratory assistants (9.8\%). There are no midwives in private clinics.

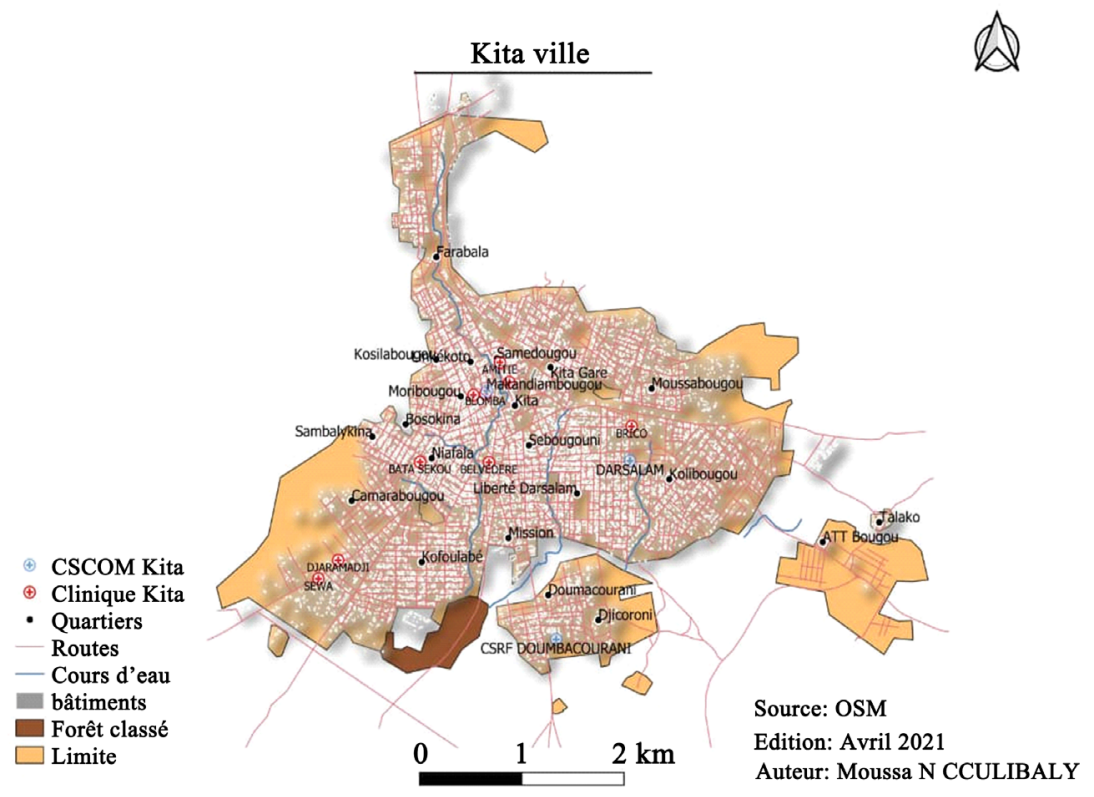

Map 1. Location of neighbourhoods and health centres in the town of Kita. 


\subsection{Quantitative Study or Questionnaire Survey}

\subsubsection{Sample Frame for the Questionnaire Survey: Drawing the "Household" Sample}

We carried out quantitative surveys among households in the target neighbourhoods of the survey. A 3-stage survey was adopted as a principle, defined as follows:

- Primary units: neighbourhoods;

- Secondary units: concessions; and

- Tertiary units: households in the concessions.

In the first stage, we selected the 13 neighbourhoods of Kita.

In the second stage, 20 concessions were drawn at random from each neighbourhood according to a sampling step and from a random starting point per neighbourhood retained in the first stage.

In the third stage, one household per concession selected in the second stage was drawn at random. The head of the household (male or female) was asked to complete the "Household" module of the questionnaire. The size of the "Household" sample was $260(13 \times 20 \times 1)$.

The women in the household aged 15 to 49 were subjected to an individual questionnaire with a view to collecting their characteristics in terms of socio-demographic and economic variables, their level of knowledge and current practice of modern contraception.

\subsubsection{Drawing of the "Women" Sample}

In the tertiary units, a three-stage process was used. In the first stage, all 260 heads of household were interviewed about the members of the unit for which they are responsible. If $1 / 10$ th of the heads of household (male or female) did not take part in the questionnaires for various reasons (refusal, absence), the actual sample size was at least 234 heads of household.

The calculation of the reference population is based on the fact that the 2009 census showed an average of 6 persons per household. If this structure has not changed between 2009 and 2020, then the reference population is $260 \times 6=1560$ persons.

In the second stage, the study proposed to interview women aged 15 - 49 from this sample of 1560 people. Women in this age group are estimated at 13,190 out of a total population of 65,908 , or $20 \%$ of the population of the town of Kita. Thus, the sample size for women is $1560 \times 0.20=312$ women aged $15-49$. Of these, 281 who have had at least one child were asked to complete the contraceptive component of the questionnaire. The overall sampling fraction $\mathrm{F}=1560 / 65$ $908=1 / 42$.

\subsection{Analytical Study}

\subsubsection{Independent Variable and Explanatory Variables: Current Use of a Contraceptive Method}

The dependent variable selected in this research is the current use or not of a modern contraceptive method by the [WRA]. It was dichotomised according to 
the requirements of logistic regression. The number zero (0) corresponded to "Yes" and the number one (1) to "No". Modern contraceptive methods included: implants, the pill, injectables (depo provera/Sayana Press), intrauterine device (IUD).

The independent variables or socio-demographic and economic characteristics are summarised in Table 1.

\subsubsection{Bivariate Analysis}

This consisted of the search for associations between this level of the dependent variable and the predictor characteristics (independent variables) by comparing proportions using the Chi-square test. CSPRO software was used to encode the data and SPSS to perform the bivariate analyses. For this purpose, the PEARSON Chi-square test, at the $5 \%$ risk level, was used.

\section{Analysis of the Results}

\subsection{Socio-Demographic and Economic Characteristics of [WRA]}

Table 2 presents the socio-demographic characteristics of [WRA].

Analysis of this table shows that $73.0 \%$ of women of childbearing age are under 35 years of age. Most of them (89.7\%) are in union. Seventy-one percent $(71.9 \%)$ have fewer than three children. Eighty percent (80.1\%) have a high level of knowledge of contraceptives: four methods or more. A large number of them $(82.9 \%)$ are in favour of family planning.

Data on the economic characteristics of women are recorded in Table 3.

$52.7 \%$ of [WRA] are illiterate and most of them $(88.3 \%)$ report having easy access to family planning information.

Table 1. List of explanatory variables.

\begin{tabular}{|c|c|c|}
\hline Explanatory variables & Definition and measures & $\begin{array}{l}\text { Expected } \\
\text { influence }\end{array}$ \\
\hline \multicolumn{3}{|l|}{$\begin{array}{l}\text { Socio-demographic } \\
\text { and economic } \\
\text { haracteristics of women: }\end{array}$} \\
\hline a) Age & Under $35($ Yes $=0 ;$ No $=1)$ & \pm \\
\hline b) Marital status & Woman in union $($ Yes $=0 ;$ No $=1)$ & \pm \\
\hline c) Number of living children & Less than 3 children $($ Yes $=0 ;$ No $=11)$ & \pm \\
\hline $\begin{array}{l}\text { d) Knowledge of } 4 \text { and more } \\
\text { modern contraceptive methods }\end{array}$ & $\begin{array}{c}\text { Knowledge of } 4 \text { and more modern } \\
\text { contraceptive methods (Yes }=0 ; \text { No }=1 \text { ) }\end{array}$ & \pm \\
\hline e) Attitude towards [FP] & Approval $($ Yes $=0 ;$ No $=1)$ & \pm \\
\hline $\begin{array}{l}\text { f) Identity of the one who decides } \\
\text { on care in the household }\end{array}$ & Head of household $($ Yes $=0 ;$ No $=1)$ & \pm \\
\hline g) Level of education & Woman knowing how to read $($ Yes $=0 ;$ No $=1)$ & \pm \\
\hline h) Access to information on [FP] & Access to information $(\mathrm{Yes}=0 ; \mathrm{No}=11)$ & \pm \\
\hline
\end{tabular}

Source: Konaté Mariam, F., 2020 
Table 2. Socio-demographic characteristics of [WRA].

\begin{tabular}{|c|c|c|}
\hline Characteristics & Workforce & Percentage \\
\hline \multicolumn{3}{|c|}{ a) Age } \\
\hline Under 35 years & 205 & 73.0 \\
\hline 35 years and over & 76 & 27.0 \\
\hline Total & 281 & 100.0 \\
\hline \multicolumn{3}{|c|}{ b) Marital status } \\
\hline Woman in union & 247 & 87.9 \\
\hline Woman living alone & 34 & 12.1 \\
\hline Total & 281 & 100.0 \\
\hline \multicolumn{3}{|c|}{ c) Number of children alive } \\
\hline Less than 3 children & 202 & 71.9 \\
\hline 3 children and more & 79 & 28.1 \\
\hline Total & 281 & 100.0 \\
\hline \multicolumn{3}{|c|}{ d) Knowledge of 4 and more modern contraceptive methods } \\
\hline High & 225 & 80.1 \\
\hline Low & 56 & 19.9 \\
\hline Total & 281 & 100.0 \\
\hline \multicolumn{3}{|c|}{ e) Attitude towards [FP] } \\
\hline Approval & 233 & 82.9 \\
\hline Disapproval & 48 & 17.1 \\
\hline Total & 281 & 100.0 \\
\hline \multicolumn{3}{|c|}{ f) Identity of the person who decides on care: } \\
\hline Head of household & 181 & 64.4 \\
\hline Woman herself & 100 & 36.6 \\
\hline Total & 281 & 100.0 \\
\hline
\end{tabular}

Source: Konaté Mariam, F., 2020.

Table 3. Economic characteristics of the [WRA].

\begin{tabular}{ccc}
\hline \multicolumn{3}{c}{ Economic characteristics } \\
\multicolumn{1}{c}{ g) Level of education } & Percentage \\
\hline Woman knowing how to read & 133 & 47.3 \\
Woman not knowing how to read & 148 & 52.7 \\
Total & 281 & 100.0 \\
Ease of access to information on [FP] & & \\
Yes & 248 & 88.3 \\
No & 33 & 11.7 \\
Total & 281 & 100.0 \\
\hline
\end{tabular}

Source: Konaté Mariam, F., 2020. 


\subsection{Current Use of a Modern Contraceptive Method by [WRA]}

Current contraceptive prevalence was $19.6 \%$ in the city of Kita (Figure 1).

This result is slightly higher than the national average of $16 \%$ according to the Institut National de la Statistique (INSTAT) du Mali (2019: p. 6). The methods most frequently used by [WRA] are the pill (49.1\%), the implant $(34.5 \%)$, the intrauterine device (10.9\%) and injections (5.5\%).

In Senegal, according to the Agence Nationale de la Statistique et de la Démographie (2020: pp. 137-195), 19 percent of women aged 15 - 49 are currently using a contraceptive method, the majority of which are modern (18 percent).

\subsection{Characteristics Associated with Current Contraceptive Use by [WRA]}

The socio-demographic characteristics associated with current use of a modern contraceptive method by [WRA] are recorded in Figure 2 below.

The proportion of women currently using a modern contraceptive method decreases with age: from $23.9 \%$ for those under $35 \%$ to $7.9 \%$ for those 35 and older. In other words, younger women are more likely to be current users of a contraceptive method than older women (Figure 2(a)). The percentage of current users of a modern contraceptive method varies by marital status. The percentage of women currently using a modern contraceptive method varies according to marital status, from $23.9 \%$ for women living alone to $7.9 \%$ for those in union (Figure 2(b)). Also, the rate of current users of a modern contraceptive method falls from $26.2 \%$ for women with fewer than three children to $2.5 \%$ for those with three or more children (Figure 2(c)). Also, the percentage of current users of a contraceptive method increases with the level of knowledge of contraceptives. It increases from $12.6 \%$ for those with a low level of knowledge to $30.4 \%$ for those with a high level of knowledge (Figure 2(d)). Thus, contraceptive knowledge is an important factor in current use of modern contraception. More current users of a modern contraceptive method (77.1\%) approve of [FP] than disapprove (40.5\%: Figure 2(e)). Figure 2(f) shows that more current users

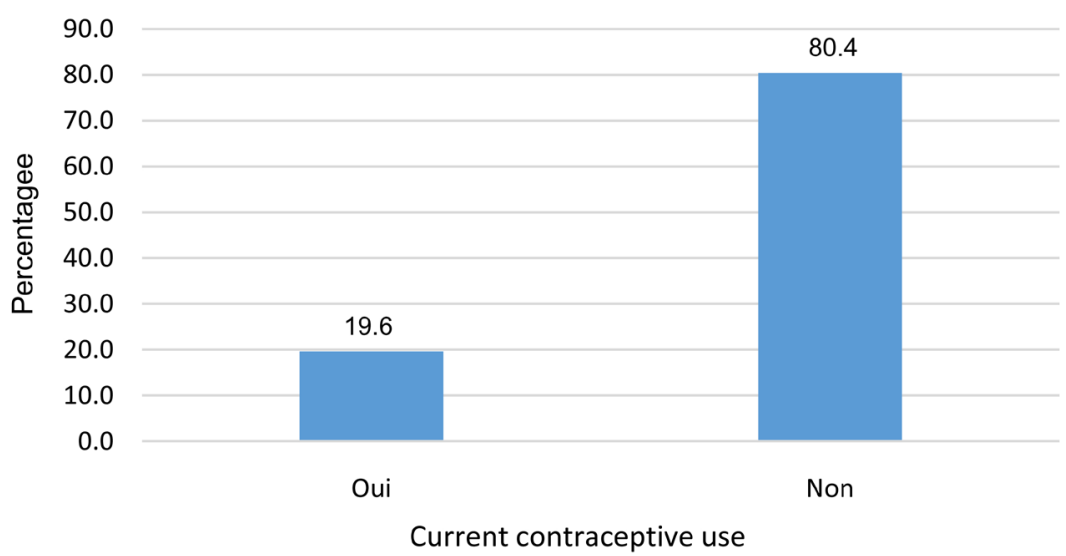

Figure 1. Current use of a contraceptive method to avoid pregnancy. Source: Konaté Mariam, F., 2020. 


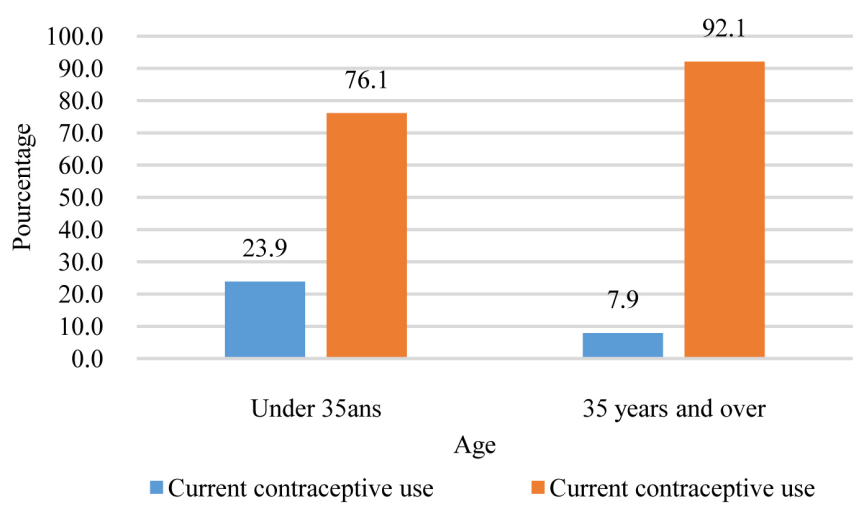

(a)

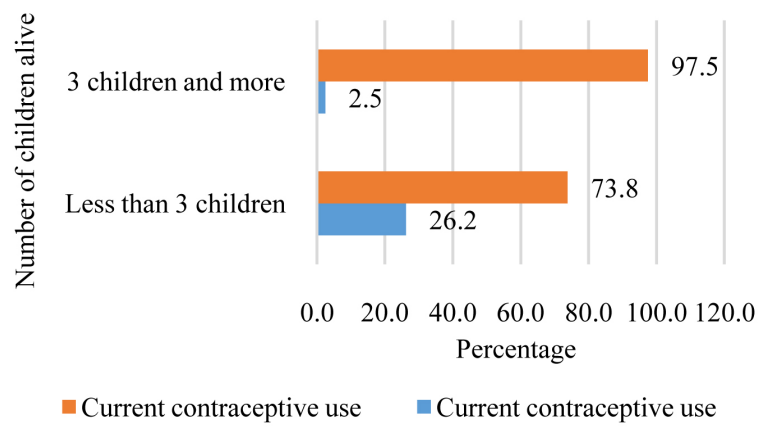

(c)

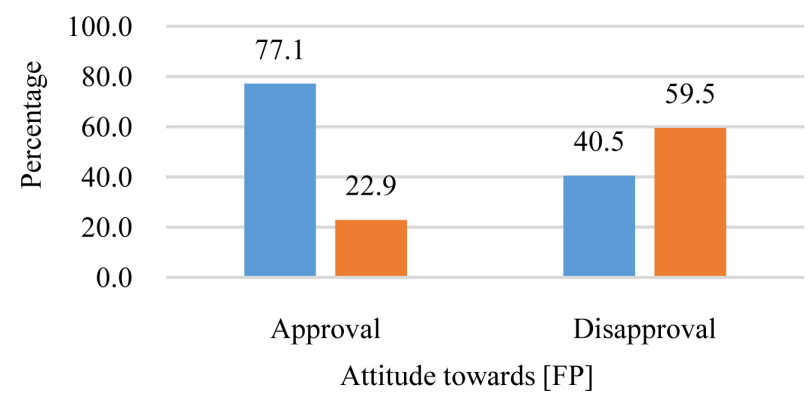

- Current contraceptive use $\quad$ Current contraceptive use

(e)

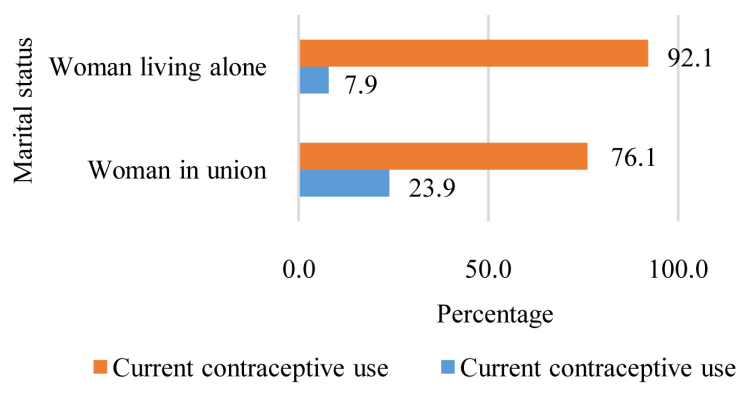

(b)

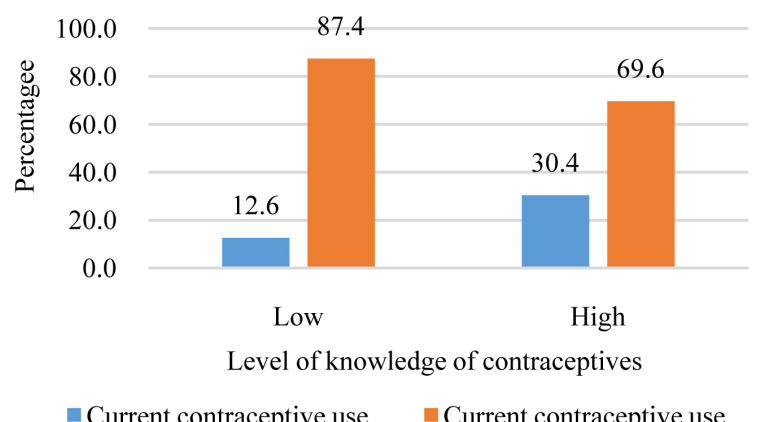

(d)

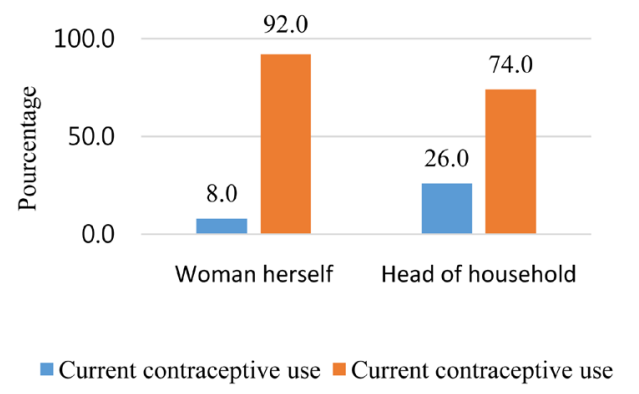

(f)

Figure 2. Current use of a modern contraceptive method by socio-demographic characteristics of [WRA]. (a) Age; (b) Marital status; (c) Number of children alive; (d) Level of knowledge of contraceptives; (e) Attitude towards [FP]; (f) Identity of the person who decides on care. Source: Konaté Mariam, F., 2020.

of a modern contraceptive method (26.0\%) are under the guardianship of the head of household than if they provide all care themselves (8.0\%).

Data on current use of a modern contraceptive method by economic characteristics of the [WRA] are shown in Figure 3.

For example, the proportion of current users of a modern contraceptive method varies by level of education. It ranges from $24.8 \%$ for women who can read and write to $14.9 \%$ for those who cannot read or write (Figure $3(\mathrm{a})$ ). Similarly, the percentage of current users of a modern contraceptive method varies according to the level of access to information on [FP]. It ranges from $21.0 \%$ for those 


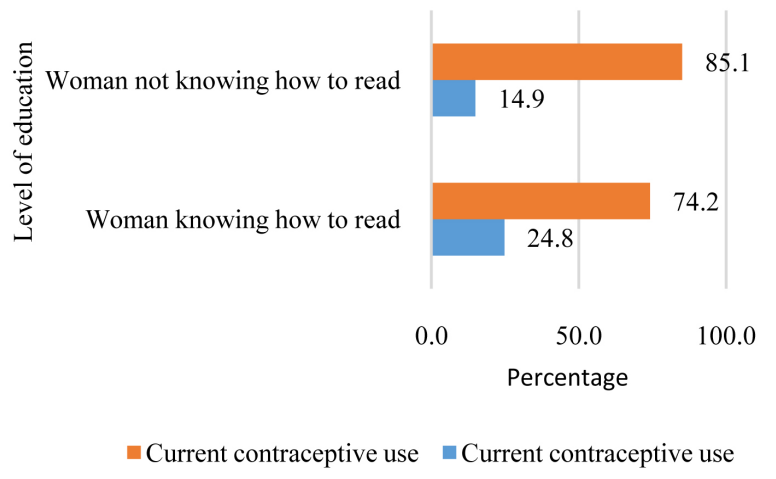

(a)

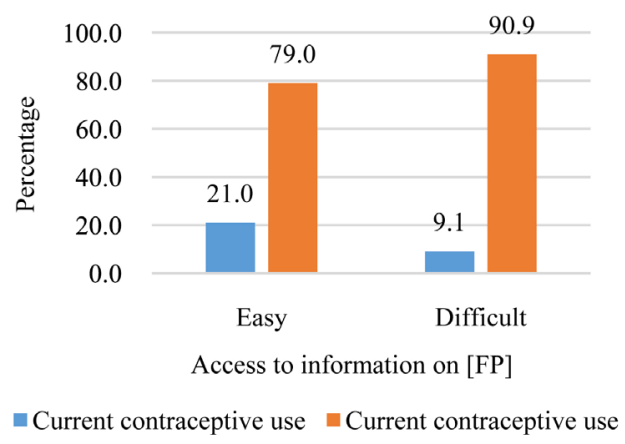

(b)

Figure 3. Current use of a modern contraceptive method by economic characteristics of [WRA]. Source: M. F. KONATE, 2020. (a) Level of education; (b) Access to information on $[\mathrm{FP}]$.

with easy access to $9.1 \%$ for those with difficult access (Figure 3(b)). In summary, it is tempting to say that all the characteristics under study have an influence on current contraceptive use by [WRA].

\subsection{Bivariate Analysis: Socio-Demographic and Economic Characteristics and Current Use of a Modern Contraceptive Method by [WRA]}

As a reminder, the Chi-square test is used to compare two proportions. It is significant when its probability (p) is less than 0.05 . The results of the Pearson Chisquare tests are shown in Table 4.

Thus, except for marital status and access to information on [FP], other characteristics such as age, number of living children, level of knowledge of contraceptives, attitude towards [FP], identity of the person who decides on care in the household and level of education are statically significantly related to the current use of a modern contraceptive method by [WRA]. Indeed, for each of the characteristics mentioned, the Pearson Chi-square test, at the 5\% error level, showed that all the values calculated, 4.403 (for the level of education) to 20.090 (for the number of living children), are higher than their theoretical values, which vary

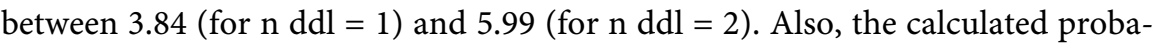
bilities are all lower than 0.05 : 
Table 4. Chi-square test results: Current use of a modern contraceptive method and socio-demographic and economic characteristics of [WRA].

\begin{tabular}{lcccc}
\hline \multicolumn{1}{c}{ Characteristics } & $\begin{array}{c}\text { Calculated } \\
\text { Pearson } \\
\text { chi-square value }\end{array}$ & $\begin{array}{c}\text { Pearson's } \\
\text { theoretical } \\
\text { chi-square value }\end{array}$ & $\begin{array}{c}\text { Number of } \\
\text { degrees of } \\
\text { freedom }\end{array}$ & $\begin{array}{c}\text { Probability }(p) \\
\text { at the error } \\
\text { threshold: } 5 \%\end{array}$ \\
\hline $\begin{array}{l}\text { Socio-demographic characteristics } \\
\text { a) Age }\end{array}$ & 9.025 & 3.84 & 1 & $p=0.000^{* *}$ \\
b) Marital status & 1.498 & 3.84 & 1 & $p=0.221 \mathrm{~ns}$ \\
c) Number of children alive & 20.090 & 3.84 & 1 & $p=0.000^{* *}$ \\
$\begin{array}{l}\text { d) Level of knowledge of } \\
\text { contraceptives }\end{array}$ & 16.203 & 3.84 & 1 & $p=0.000^{* *}$ \\
e) Attitude towards [FP] & 12.290 & 5.99 & 2 & $p=0.002^{* *}$ \\
$\begin{array}{l}\text { f) Identité de celui } \\
\text { qui décide des soins }\end{array}$ & 13.209 & 3.84 & 1 & $p=0.000^{* *}$ \\
& Economic characteristics & & \\
$\begin{array}{l}\text { g) Level of education } \\
\text { h) Access to information } \\
\text { on [FP] }\end{array}$ & 4.403 & 3.84 & 1 & $p=0.036^{* *}$ \\
\hline
\end{tabular}

**: significant; ns: no significant; Source: Konaté Mariam, F., 2020.

- $p=0.000$ for characteristics such as age, number of living children, level of knowledge of modern contraceptives and identity of the person who decides on all care in the household;

- $p=0.036$ for education level;

- $p=0.002$ for attitude towards [FP].

Given the conditions for the Chi-square values and the calculated probabilities, the hypothesis of independence between these predictor characteristics and current contraceptive use must be rejected. Therefore, these characteristics are statistically significantly related to this dependent variable.

In summary, the socio-demographic and economic characteristics of [WRA] not associated with current use of modern contraception are: marital status $(p=0.221>$ $0.05)$ and access to information on [FP] $(p=0.106>0.05)$.

On the other hand, variables as age $(p=0.000<0.05)$, marital status $(p=0.221$ $<0.05)$, number of living children $(p=0.000<0.05)$ are associated with the current use of contraception, and that in a statistically significant way. A similar result was found for the following variables: level of knowledge of contraceptives, $(p=0.000<0.05)$, attitude towards [FP] $(p=0.002<0.05)$, identity of the care giver $(p=0.000<0.05)$ and level of education $(p=0.036<0.05)$.

\section{Discussion of the Results}

Firstly, our study did not find statistically significant associations between a woman's likelihood of being a user and characteristics such as marital status and [WRA] access to information on [FP]. Speaking of the relationship between marital sta- 
tus and contraceptive use, the Institut National de la Statistique du Niger (2013: pp. 8-40), revealed that the contraceptive prevalence of women in union is practically no different from that of all women. In contrast, in Senegal, according to the Agence Nationale de la Statistique et de la Démographie (2020), women who are not in union and who are sexually active have a higher percentage of use of a contraceptive method (45\%) than those in union (27\%). According to Fassassi (2007: pp. 35-40), the relationship between marital status and contraceptive practice is close in Africa. Paradoxically, the management of the risk of conception is more pronounced among single women or women who have broken up than among women in union. Divorced, widowed or separated women have a stricter control of the risk of conception, probably more for social reasons but perhaps also because of the greater difficulty of raising a child alone.

According to Mbakoptchoua (2010: pp. 40-50), it was found that women in need who have access to information on [FP] would be more likely to use contraception than others who do not. This contradicts our results in this sense.

Secondly, our study found statistically significant associations between a woman's likelihood of being a current user of a contraceptive method and socio-demographic characteristics such as age, number of living children, level of knowledge about contraceptives, attitude toward [FP], and the identity of the person responsible for all care in the household.

Our finding with respect to age was confirmed by Demographic and Health Surveys in several African countries south of the Sahara. Thus the Institut National de la Statistique (INS) de la Côte d'Ivoire (2013: pp. 9-17), found that the prevalence of modern contraception varies according to the age group of the woman. The highest proportion of users (ranging from 12\% to 15\%) is at ages 20 - 44, the peak fertility period. Among women under 20 and those aged 45 and over, the rates are relatively lower: $7 \%$ in the $15-19$ age group, and $6 \%$ at 45 49. According to the Institut National de la Statistique (INS) du Niger (2013: pp. 14-20), the trend in current contraceptive use by age of women in union is not very different from those of women overall. Modern prevalence is highest in the 25 - 29 age group (16\% in both cases). In Chad, the Institut National de la Statistique (2015), found that contraceptive prevalence among women in union increases steadily from age group 15 - 19 (3\%) to age group 30 - 34 (8\%). Beyond that, the proportions decrease steadily to $3 \%$ at ages 45 - 49. Finally, the Agence Nationale de la Statistique et de la Démographie (ANSD) du Sénégal (2020), showed that modern contraceptive use among women aged 15 - 49 increases with the age of the woman, reaching its highest level in the 35 - 39 age group (29\%). From the age of 40 onwards, there is a decline in contraceptive use for modern methods to $25 \%$ among women aged $40-44$ and $24 \%$ among those aged $45-49$.

Our study found statistically significant associations between current use of a modern contraceptive method and the number of live children of [WRA]. This result has been confirmed by numerous studies. For example, according to the Institut National de la Statistique (INSTAT) du Mali (2014), modern contracep- 
tive use is lower among women who have had no live births (5\%) than among women who have three or more children (11\%). Also, according to the Institut National de la Statistique, Ministère du Plan et du Développement Economique Conakry, Guinea (2019), modern contraceptive prevalence increases with the number of live children, from $8 \%$ among women in unions with no children to $12 \%$ among those with five or more children. In Côte d'Ivoire, the Institut National de la Statistique (INS) de la Côte d'Ivoire (2013), finds that a woman's number of living children appears to be a key determinant of modern contraceptive use. Women without children, who are generally younger, are the least frequent users of modern contraception (3\%). In Chad, the Institut National de la Statistique (2015), finds that contraceptive prevalence increases with the number of living children, from $1 \%$ among those with no living children to $7 \%$ among those with five.

Our research has shown that [WRA] knowledge of contraceptives is an important factor in current contraceptive use. In this regard, Matungulu et al (2015), found that women with a high level of contraceptive knowledge had $(p<0.001)$ a 1, 87 times higher probability of being users of modern contraceptive methods than those with a low level of contraceptive knowledge. This is because women with a high level of knowledge know where they can get them, understand their side effects and know how to use them.

Our study shows that the attitude of [PAF] towards [FP] is a major indicator of current contraceptive use. In this regard, according to Matungulu et al. (2015), women with a favourable attitude towards contraceptive methods were ten times more likely to use modern methods of contraception than those with an unfavourable attitude. Alemayehu et al. (2012), went on to note that women who discussed contraception with their partners were 2.2 times more likely to use family planning. Contraception was about 2.6 times more likely among married women whose partners supported family planning use. Makhtar mbacke leye et al. (2015: pp. 108-117) found that women of reproductive age who were satisfied with the quality of contraceptive services were more likely to use modern contraceptive methods.

Our research also indicated that the identity of the caregiver is a key factor in current contraceptive use by [WRA]. This result is largely confirmed by Matungulu et al. (2015), who specified that spousal support $(p<0.001)$ was significantly associated with the use of modern contraceptive methods. Our result is, however, contradicted by Makhtar mbacke leye et al. (2015), who found that women of reproductive age with decision-making power were 2.2 times more likely to use modern contraceptive methods than those who were under guardianship.

Finally, our research revealed statistically significant associations between a woman's likelihood of being a current user of a contraceptive method and her level of education. In this regard, results from the Institut National de la Statistique (INSTAT) du Mali (2014), indicated that the level of education appears to be the most important determinant of contraceptive use, with prevalence ranging from $8 \%$ among women with no education to $13 \%$ among those with prima- 
ry education and $27 \%$ among those with secondary education or higher. This result was confirmed by data from the Institut National de la Statistique, Ministère du Plan et du Développement Economique Conakry, Guinea (2019), where the level of modern contraceptive use increases significantly with the level of education, from $9 \%$ among women in union and with no education, to $12 \%$ among those with primary education and 19\% among those with secondary education or higher. Our result was contradicted by that of the Institut National de la Statistique (INS) du Tchad (2015), which indicates that modern contraceptive prevalence is much higher among women with no education (21\%) than those with higher education (8\%) than those with primary education (3\%). In Senegal, the Agence Nationale de la Statistique et de la Démographie (2020), found that women with primary education use modern contraception much more (34\% versus $21 \%$ among those with no education and $29 \%$ among those with intermediate/ secondary education or higher). An identical result was obtained by the Institut National de la Statistique (INS) du Niger (2013: pp. 8-40), which states that the level of education appears to be the most determining factor in the use of a contraceptive method. Thus, the proportions of users are $10 \%, 18 \%$ and $30 \%$ respectively for women with no education, women with primary education and women with secondary education. In Côte d'Ivoire, the level of education of women is another important differential factor. Contraceptive prevalence is strongly associated with education level: among women with secondary or higher education, $22 \%$ currently use a modern method, compared to $17 \%$ among women with primary education and $9 \%$ among those with no education (Institut National de la Statistique, 2013).

\section{Conclusion}

The study was limited by the growing insecurity in the circle of Kita. Thus, the study took place only in town. In addition, the data collected was largely based on the declarations of the women surveyed, a situation that could lead to observation bias despite the efforts of the investigators to minimise this source of error.

The methodological approach was based on a literature search, a questionnaire survey on a sample of 281 [WRA] and a bivariate analysis.

The study revealed that contraceptive prevalence in the city of Kita is relatively higher (19.6\%) than the national average (16\%). Socio-demographic characteristics such as age, number of living children, level of knowledge about contraceptives, attitude towards [FP] and identity of the person in charge of all care in the household are associated with current contraceptive use by [WRA]. Similarly, education level is statistically significantly related to current contraceptive use by [WRA]. In contrast, marital status and access to information about [FP] are not associated with current contraceptive use by [WRA].

These results confirm our working hypothesis: "Socio-demographic and economic characteristics are variously and significantly associated with current use 
of modern contraception by [WRA] in Kita. These associated characteristics are one of the key indicators of the degree of success of any family planning program. Their determination is an essential step for the implementation of [FP] programs in the city of Kita. In perspective, this research on the determinants of current modern contraceptive use must be supported by a qualitative study.

\section{Conflicts of Interest}

The authors declare no conflicts of interest regarding the publication of this paper.

\section{References}

Agence Nationale de la Statistique et de la Démographie (ANSD) du Sénégal (2020). Demographic and Health Survey 2018 (pp. 137-195). Agence Nationale de la Statistique et de la Démographie (ANSD) du Sénégal.

Alemayehu, M., Belachew, T., \& Tilahun T. (2012). Factors Associated with Utilization of Long Acting and Permanent Contraceptive Methods among Married Women of Reproductive Age in Mekelle Town, Tigray Region, North Ethiopia. BMC Pregnancy Childbirth, 12, Article No. 6. https://doi.org/10.1186/1471-2393-12-6

Fassassi, R. (2007). Les facteurs de la contraception en Afrique de l'Ouest et en Afrique centrale au tournant du siècle. Rapport de synthèse (pp. 35-40). École Nationale Supérieure de l'Électronique et de ses Applications (ENSEA)/Centro Universitário de Estudos e Pesquisas sobre Desastres (CEPED).

Institut National de la Statistique (INS) du Tchad (2015). Demographic and Health Survey Rapport (pp. 1-11). Institut National de la Statistique (INS) du Tchad.

Institut National de la Statistique (INSTAT) du Mali (2014). Demographic and Health Survey 2012-2013 (pp. 77-120). Institut National de la Statistique (INSTAT) du Mali.

Institut National de la Statistique (INSTAT) du Mali (2019). Demographic and Health Survey 2018 (p. 6). Institut National de la Statistique (INSTAT) du Mali.

Institut National de la Statistique (INS) du Niger (2013). Demographic and Health Survey 2012 (pp. 8-40). Institut National de la Statistique (INS) du Niger.

Institut National de la Statistique (INS) de la Côte d'Ivoire (2013). Demographic and Health Survey (pp. 9-17). Institut National de la Statistique (INS) de la Côte d'Ivoire.

Institut National de la Statistique, Ministère du Plan et du Développement Economique Conakry, Guinea (2019). Demographic and Health Survey (pp. 163-170). United States Agency for International Development (USAID)/World Bank.

Makhtar mbacke leye, M., Faye, A., Diongue, M., Wone, I., Seck, I., Ndiaye, P., \& Tal, D., (2015). Déterminants de l'utilisation de la contraception moderne dans le district sanitaire de Mbacké (Sénégal). Santé Publique, 27, 108-117.

https://doi.org/10.3917/spub.151.0107

Matungulu, C., Kandolo, S. I., Mukengeshay, A.N., Nkola, A. M., Mpoy, D. I., Mumba, S. K., Kabamba, J. N. K. C. F., \& Malongakaj, J. N. K. C. F. (Sous la direction de GENDREAU Francis) (2015). Déterminants de l'utilisation des méthodes contraceptives dans la zone de santé Mumbunda à Lubumbashi, République Démocratique du Congo. The Pan African Medical Journal, 22, Article No. 329. https://doi.org/10.11604/pamj.2015.22.329.6262 https://www.ncbi.nlm.nih.gov/pmc/articles/PMC4769809

Mbakoptchoua, C. A. (2010). Facteurs explicatifs des besoins non satisfaits en matière de 
planification familiale chez les femmes en union au Cameroun (pp. 40-50). Mémoire de Master IFORD.

Ministry of Land Use and Population, Population Projections (2020). Report (pp. 14-20). Bamako: National Directorate of Population.

UNFPA (2017). Santé et droits sexuels et de la procréation des adolescentes au Mali (pp. 18-22). Bureau Afrique de l'Ouest 09 BP 1660 Ouagadougou.

Vimard, P. (2007). Synthèse: Entre présent contrasté et avenir incertain: La démographie, la santé de la reproduction et le développement en Afrique subsaharienne. In L'Afrique face à ses défis démographiques, un avenir incertain (pp. 350-353). sous la direction de FERRY B., Agence Française de Développement (AFD), Centro Universitário de Estudos e Pesquisas sobre Desastres (CEPED), Éditions Karthala. 